\title{
Inhibition of PKR by Viruses
}

\author{
Teresa Cesaro and Thomas Michiels* \\ de Duve Institute, Université catholique de Louvain, Brussels, Belgium
}

Cells respond to viral infections through sensors that detect non-self-molecules, and through effectors, which can have direct antiviral activities or adapt cell physiology to limit viral infection and propagation. Eukaryotic translation initiation factor 2 alpha kinase 2, better known as PKR, acts as both a sensor and an effector in the response to viral infections. After sensing double-stranded RNA molecules in infected cells, PKR selfactivates and majorly exerts its antiviral function by blocking the translation machinery and inducing apoptosis. The antiviral potency of PKR is emphasized by the number of strategies developed by viruses to antagonize the PKR pathway. In this review, we present an update on the diversity of such strategies, which range from preventing double-stranded RNA recognition upstream from PKR activation, to activating elF2B downstream from PKR targets.

OPEN ACCESS

Edited by:

Zhi-Ming Zheng,

National Cancer Institute (NCl),

Frederick, United States

Reviewed by:

Jinwei Zhang,

National Institutes of Health $(\mathrm{NIH})$,

United States

Anna Salvetti,

Centre International de Recherche en Infectiologie (CIRI), France

*Correspondence:

Thomas Michiels thomas.michiels@uclouvain.be

Specialty section: This article was submitted to

Virology,

a section of the journal

Frontiers in Microbiology

Received: 11 August 2021 Accepted: 29 September 2021

Published: 25 October 2021

Citation:

Cesaro T and Michiels T (2021) Inhibition of PKR by Viruses.

Front. Microbiol. 12:757238.

doi: 10.3389/fmicb.2021.757238
Keywords: innate immunity, integrated stress response, mRNA translation, innate immunity evasion, viral proteins, double-stranded RNA

\section{INTRODUCTION}

\section{PKR: A Cornerstone in the Integrated Stress Response}

The integrated stress response (ISR) is a signaling pathway that optimizes the cellular response to stress and aims to restore homeostasis after different types of stress (Pakos-Zebrucka et al., 2016). It relies on the detection of cellular stresses by 4 protein kinases, which are referred to as eIF2 $\alpha$ kinases (EIF2AK) because they phosphorylate a common target: eukaryotic translation initiation factor 2 subunit alpha (EIF2S1 or eIF2 $\alpha$ ). eIF2 $\alpha$ is a subunit of eIF2, which contributes to the formation of the ternary mRNA translation initiation complex. Phosphorylation of eIF2 $\alpha$ Ser51 by eIF2 $\alpha$ kinases tightens the interaction between eIF $2 \alpha$ and eIF2B, a guanine exchange factor for eIF2, thereby preventing recycling of GDP-bound eIF2 $\alpha$ and thus blocking translation initiation (Sudhakar et al., 2000). Translation blockade results in the rapid formation of stress granules (SGs; Anderson and Kedersha, 2008; McCormick and Khaperskyy, 2017).

While EIF2AK1 (HRI) is mostly sensing oxidative stress, EIF2AK3 (PERK) endoplasmic reticulum stress, and EIF2AK4 (GCN2) amino acid deprivation, EIF2AK2, better known as $\mathrm{PKR}$, is an interferon-induced protein kinase activated in primis by viral double-stranded (ds) RNA molecules (Taniuchi et al., 2016). PKR was identified nearly 50 years ago by the groups of D.H. Metz (Friedman et al., 1972) and I. Kerr (Kerr et al., 1977). In the 90s, human PKR cDNA was cloned at the Pasteur Institute (Meurs et al., 1990), opening the way to detailed molecular analysis of the PKR activation pathway and of the diversity of PKR activities.

PKR is a 551 amino acid-long protein, containing a C-terminal kinase domain and two $\mathrm{N}$-terminal double-stranded RNA-binding motifs (DRBMs). It is mostly cytoplasmic although some PKR has been detected in the nuclear fraction (Jeffrey et al., 1995; Garcia et al., 2006). It is noteworthy that PKR as well as other proteins involved in innate antiviral immunity can 
be incorporated in stress granules together with translation initiation factors, SG-forming proteins and mRNA (Langereis et al., 2013; Onomoto et al., 2014). Stress granules are regarded as platforms required for innate immunity initiation and for activation of PKR itself (Onomoto et al., 2014; Reineke et al., 2015). Prolonged PKR activation can promote cell apoptosis. Both inhibition of viral mRNA translation and apoptosis of infected cells are effector mechanisms that critically limit viral spread in an infected host (Garcia et al., 2007).

PKR is also closely linked to p53. On the one hand, activated p53 upregulates the transcription of the gene coding for PKR, and PKR pro-apoptotic activity accounts for part of the tumor suppressor function of p53 (Yoon et al., 2009). On the other hand, PKR was shown to physically interact with p53 and to phosphorylate p53 in vitro (Cuddihy et al., 1999).

PKR further contributes to the inflammatory response by promoting NFKB activation through the activation of NIK and IKKB (Zamanian-Daryoush et al., 2000) and to the IFN response, by stabilizing IFN- $\beta$ mRNA (Schulz et al., 2010).

PKR is thus a corner stone in the ISR as it links cellular stresses, such as DNA damage, to cell survival, innate immunity, and in particular antiviral response.

Given its critical role, PKR requires fine tuning. Excessive PKR activity can be detrimental, as is observed in AicardiGoutières syndrome patients where mutations in the adenosine deaminase 1 (ADAR1) lead to increased levels of endogenous dsRNA, thereby triggering PKR activation and uncontrolled IFN production (Chung et al., 2018).

\section{Triggers of PKR Activation}

EIF2AK2, the gene encoding PKR, is constitutively expressed in mammalian cells. Its transcription can substantially be stimulated by IFN treatment because the promoter contains an IFN-stimulated response element (ISRE; Kuhen and Samuel, 1997). Splice variants have been described that affect exon 2 in the 5'UTR, which likely affect cell type-dependent translation (Kawakubo et al., 1999), or exon 7 in the coding region, which potentially generate a dominant-negative form of PKR ( $\mathrm{Li}$ and Koromilas, 2001). The physiological impact of these variations however remains to be defined. Importantly, PKR is expressed as a latent enzyme, which requires further stimulation to become enzymatically active.

The best-characterized PKR activator is dsRNA, a typical by-product of RNA virus replication. Interestingly, dsRNA is also detectable by immunofluorescence in the cytoplasm of cells infected with DNA viruses, such as herpesviruses (Weber et al., 2006), where it was proposed to result from cytoplasmic relocalization of a pseudogene-encoded ribosomal RNA (Chiang et al., 2018). DsRNA can also be of endogenous origin, stemming in human cells from the annealing of mitochondrial or Alu sequence-derived transcripts. In physiological conditions, the concentration of endogenous dsRNA molecules is normally limited under the PKR activation threshold thanks to the dsRNA destabilizing activity of adenosine deaminase RNA specific 1 (ADAR1; Toth et al., 2009; Li et al., 2010; Okonski and Samuel, 2013).

Recently, circular RNAs, which are generated in the cell by a back-splicing mechanism, were shown to be potent PKR inhibitors. Such circular RNAs have a high propensity to form short (16-26 pb-long), imperfect, intramolecular RNA duplexes that inhibit PKR activity (Liu et al., 2019). Interestingly, upon viral infection, such circular RNAs undergo rapid degradation by RNase L (for review see Drappier and Michiels, 2015; Gusho et al., 2020), thus restoring PKR activity (Liu et al., 2019).

Other interactors, including RNAs and proteins, were shown to regulate PKR activation. Non-coding RNA 886 (nc886) was first identified as an inhibitor of PKR activation by dsRNA (Lee et al., 2011; Jeon et al., 2012). nc886 RNA was however shown to act as a PKR activator in stimulated T lymphocytes (Golec et al., 2019).

Proteins were also shown to regulate PKR activation by direct protein-protein contact.

Protein activator of interferon (IFN)-induced protein kinase EIF2AK2 (PRKRA) most commonly referred to as PACT (RAX in the mouse) was described as a PKR activator. PACT and PKR can interact through direct protein-protein interaction, via their dsRNA-binding domains (Huang et al., 2002). Direct interaction with PACT is sufficient to promote PKR activation in vitro and in cells.

Interestingly, another dsRNA-binding protein, TRBP can interact with both PACT and PKR, thus creating a complex regulatory network (Park et al., 1994). Upon stress, phosphorylation of PACT favors the release of PACT from the TRBP-PACT complex, thereby increasing the interaction of PACT with PKR and the consequent PKR activation (Singh et al., 2011).

\section{PKR Autoactivation Cascade}

In response to dsRNA molecules or to other activation signals, PKR undergoes an autoactivation process. In the inactivated state, DRBM2 and probably DRBM1 keep the protein in a closed conformation through interaction of DRBMs with the kinase domain (Robertson and Mathews, 1996; Nanduri et al., 2000). Binding of dsRNA molecules to DRBMs causes the release of these domains from the kinase domain and the consequent dimerization and autophosphorylation of the protein (Garcia et al., 2006). Phosphorylation of threonines 446 and 451, considered as a primary marker of PKR activation, is crucial for PKR-mediated recognition of substrates like eIF2 $\alpha$ and the consequent inhibition of mRNA translation (Dey et al., 2005). Autophosphorylation of other PKR residues, such as Ser33 (Wang et al., 2017) or Ser6 (Cesaro et al., 2021), likely results in fine tuning of PKR activity through a network of positive and negative feedbacks.

\section{MECHANISMS OF PKR INHIBITION BY VIRUSES}

As outlined above, PKR is a critical player of the antiviral response and, since it acts by inhibiting mRNA translation, triggering apoptosis, and amplifying the IFN response, PKR acts as a broad range viral antagonist, inhibiting the replication of both RNA and DNA viruses. 
As expected from the potent antiviral activity of PKR, many viruses evolved to counteract PKR activity by using their own viral products or by hijacking cellular proteins, acting at the different steps in the cascade of PKR activation (Figure 1). Previous reviews provide a broad view on the biology of PKR, its activation process, its many activities (Garcia et al., 2006, 2007), and its antiviral functions and viral countermeasures (Dauber and Wolff, 2009; Walsh and Mohr, 2011; Dabo and Meurs, 2012; Dzananovic et al., 2018).

This review provides an update on the diversity of mechanisms adopted by viruses to inhibit the PKR pathway, from upstream triggers to downstream targets.

Table 1 provides a list of viral products reported to be involved in evasion of the PKR response. The paragraphs below and Figure 1 review the different mechanisms by which these viral products counteract the PKR pathway.

\section{dsRNA Sequestration, Masking, or Degradation}

A key mechanism used by viral proteins to inhibit PKR-mediated antiviral response is hiding or sequestering dsRNA molecules that would otherwise activate PKR.
An example of such a dsRNA sequestering viral proteins is Middle East respiratory coronavirus (MERS-CoV) protein 4a (Rabouw et al., 2016). Historical examples of viral dsRNAbinding proteins include the E3L protein of vaccinia virus (VACV; Romano et al., 1998), the NS1 protein of Influenza virus (Dauber et al., 2006), and the $\sigma 3$ outer capsid protein of mammalian reovirus that was shown to compete with PKR for dsRNA binding via its C-terminal DRBM (Jacobs and Langland, 1998). For the latter three proteins however, PKR inhibition was later shown to rely on their ability to form direct protein-protein contacts with PKR (Davies et al., 1993; Guo et al., 2021), sometimes in a strain-dependent manner (Min et al., 2007).

Interestingly, some viruses evolved to restrict PKR activation by limiting dsRNA availability through degradation. This was shown for the nsp15 endonuclease of Infectious Bronchitis Virus (IBV), an avian coronavirus (Gao et al., 2021; Zhao et al., 2021), and for the virion host shutoff (VHS) tegument protein, a ribonuclease encoded by herpes simplex 1 (Dauber et al., 2011).

In the case of Human parainfluenza virus type 3 (HPIV3), a negative-stranded RNA virus, association of nucleo $(\mathrm{N})$ and phospho (P) proteins is responsible for the formation of inclusion bodies,

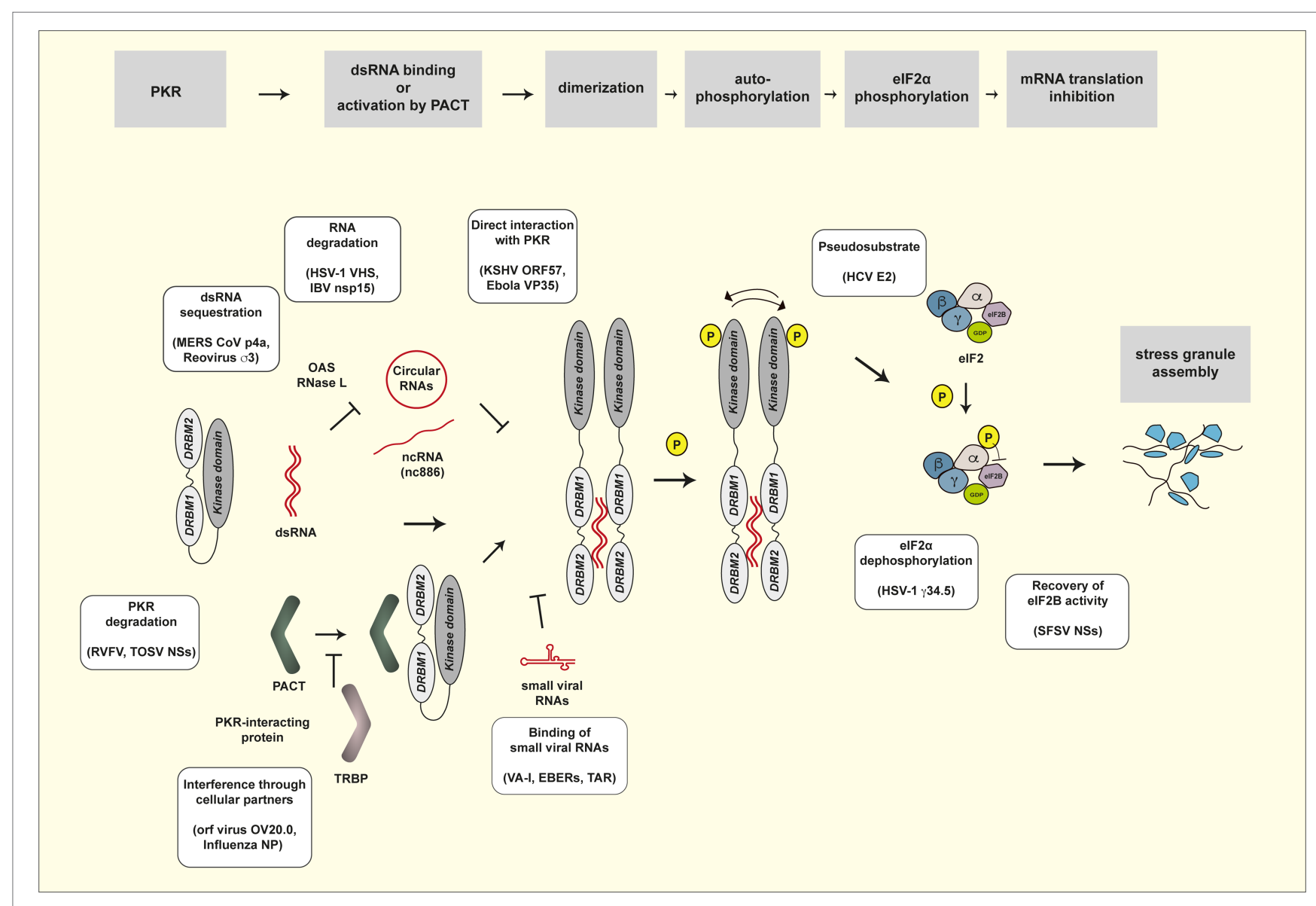

FIGURE 1 | PKR activation pathway and viral countermeasures. Steps of the PKR activation pathway are framed in gray. Viral evasion mechanisms are presented in yellow frames. See Table $\mathbf{1}$ for a list of viral products involved in evasion of PKR activity. 
TABLE 1 | Strategies developed by viruses to escape PKR-mediated antiviral response.

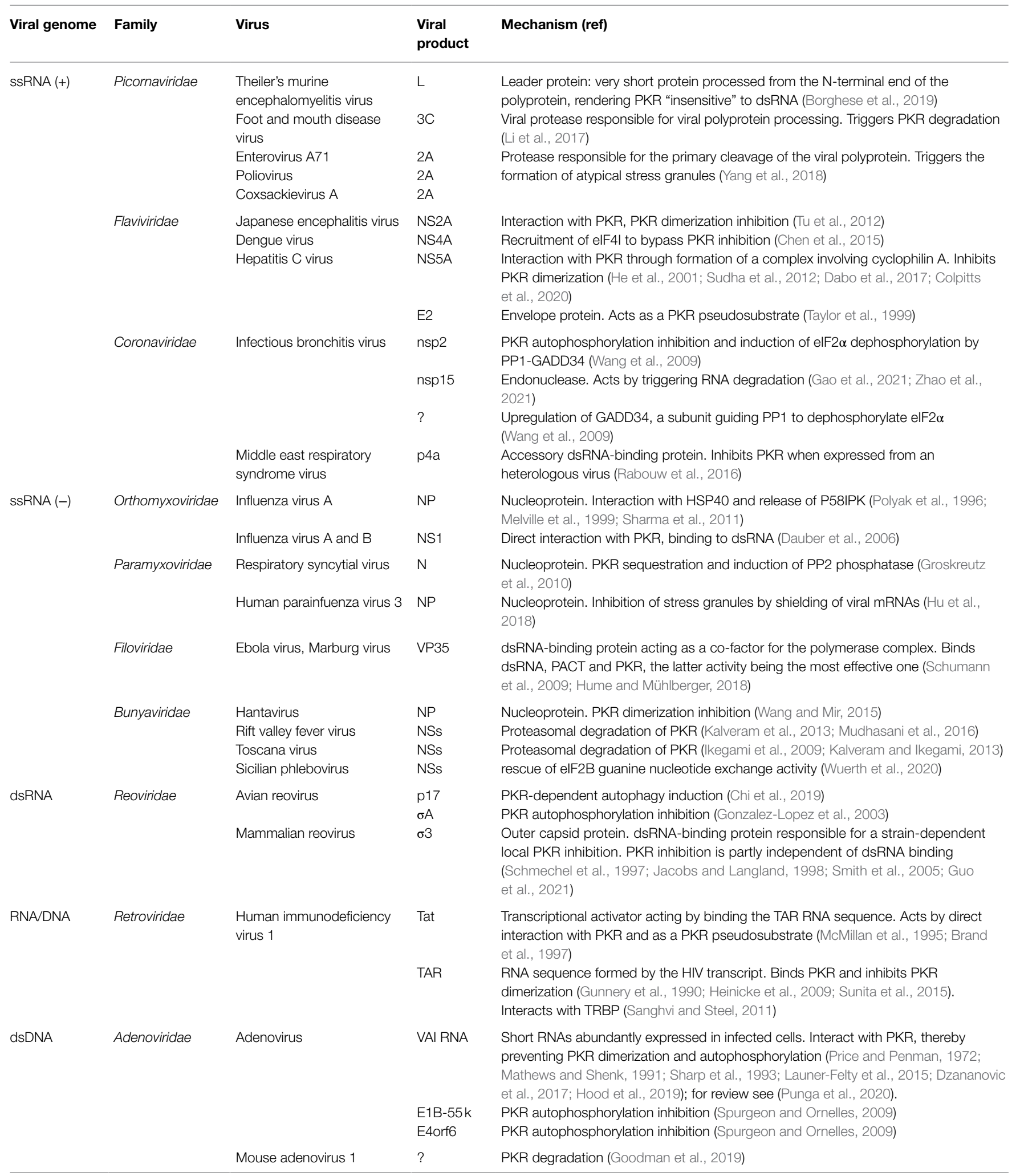


TABLE 1 | Continued

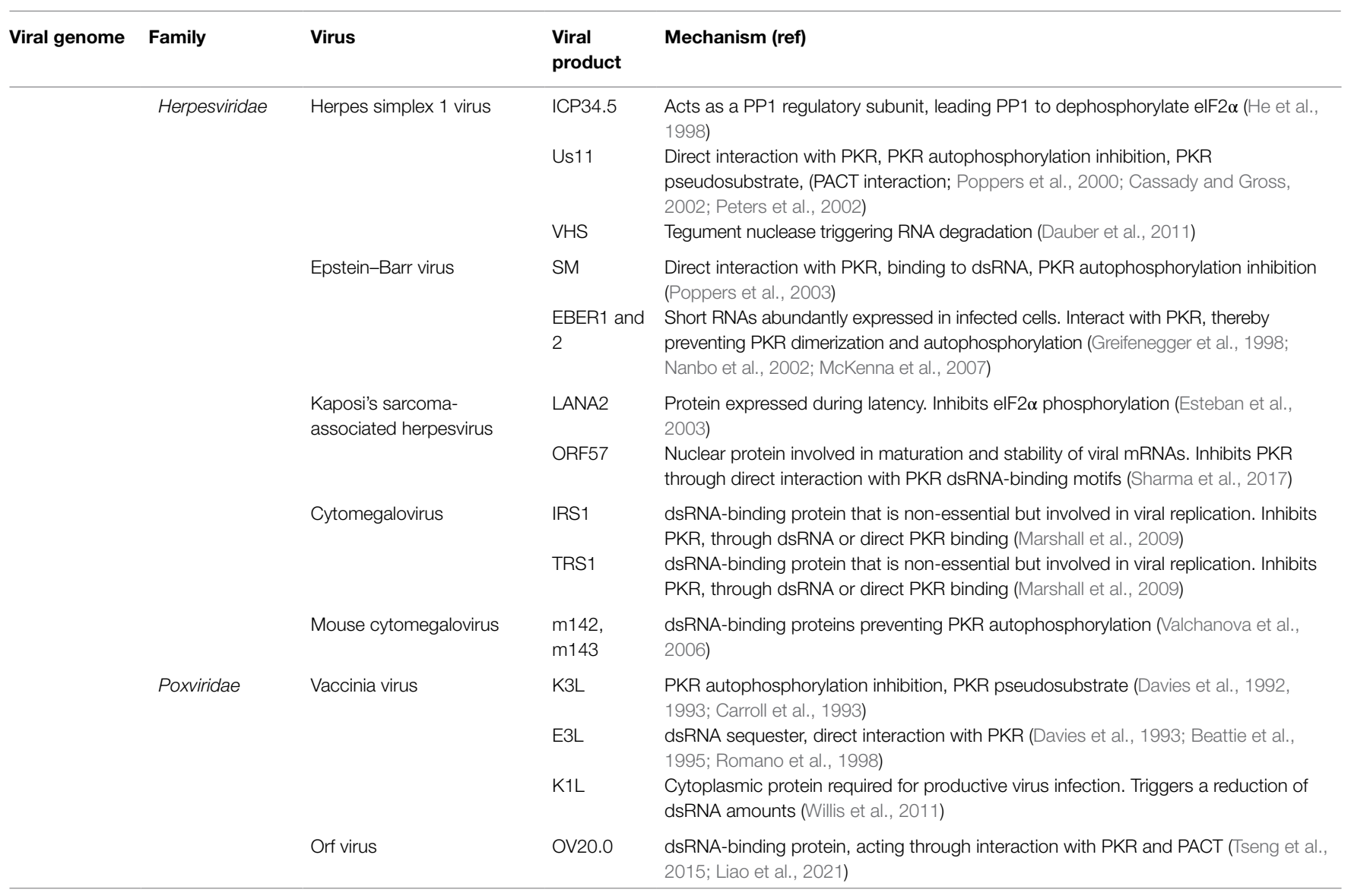

which shield newly synthesized viral RNA, thereby inhibiting PKR activation and formation of stress granules. In this case however, mRNA, which is shielded by inclusion bodies, rather than dsRNA, is likely to be the trigger of PKR activation (Hu et al., 2018).

\section{PKR Degradation}

Toscana virus (TOSV) and Rift valley fever virus (RVFV) are two members of the Bunyaviridae family, which trigger proteasomal degradation of PKR through their non-structural NSs proteins (Ikegami et al., 2009; Kalveram et al., 2013). TOSV NSs was shown to interact with PKR but it is unclear how this interaction triggers proteasomal degradation of PKR (Kalveram and Ikegami, 2013). In the case of RVFV, NSs carries out this activity by binding to PKR and to F-box and WD repeat domain containing 11 (FBXW11), thus assembling an E3 ubiquitin ligase complex, which triggers PKR polyubiquitination and its consequent degradation by the proteasome (Mudhasani et al., 2016).

Adenovirus late viral proteins E1B-55k and E4orf6 are both multifunctional proteins that can block $\mathrm{p} 53$-dependent apoptosis, interfere with mRNA export from the nucleus, and regulate viral replication. In addition, these proteins are involved in the formation of E3 ubiquitin-protein ligase complex with cullin 5, Ring-box 1, and elongins B and C. E1B-55k and E4orf6 inhibit PKR and eIF $2 \alpha$ phosphorylation at late stages of infection in a cullin 5-dependent manner, suggesting that these proteins may act by triggering PKR degradation. However, their PKR antagonist activity may also depend on their influence on subcellular RNA trafficking (Spurgeon and Ornelles, 2009). Proteasome-dependent degradation is, however, more likely as this mechanism was recently documented in the case of the mouse adenovirus type 1 (Goodman et al., 2019).

A typical way used by picornaviruses and other positive-stranded RNA viruses to escape immunity is to cleave immune sensor and effector proteins with proteases that are encoded by these viruses to process their own polyprotein. In the case of enteroviruses, such as poliovirus, coxsackievirus, or enterovirus A-71, a recent high-throughput study identified hundreds of host proteins that are substrates of $2 \mathrm{~A}$ or $3 \mathrm{C}$ proteases. $\mathrm{PKR}$ was surprisingly not in the list (Saeed et al., 2020). In contrast, 3C protease of another picornavirus, foot and mouth disease virus (FMDV), was shown to trigger PKR degradation. In this case however, PKR was not a direct substrate of protease $3 \mathrm{C}$ but PKR degradation occurred through the lysosomal pathway (Li et al., 2017).

\section{Inhibition of PKR Dimerization and Autophosphorylation}

Many viral products were shown to inhibit PKR activation and autophosphorylation without evidence for direct interaction with dsRNA or with PKR itself. These viral products likely 
prevent dsRNA binding, dimerization, and/or autophosphorylation of PKR but the precise mechanism by which they act is not fully elucidated.

These include, for instance, $\mathrm{m} 142$ and $\mathrm{m} 143$ of the murine cytomegalovirus (MCM; Valchanova et al., 2006), or nsp2 of Infectious bronchitis virus (IBV; Wang et al., 2009). Hantavirus escapes PKR-mediated antiviral response by inhibiting PKR dimerization with its nucleoprotein (NP). However, competitive binding of NP to dsRNA or to PKR itself could not be documented (Wang and Mir, 2015).

\section{PKR Inhibition Through Direct Interaction Interacting Viral RNAs}

Inhibition of PKR by physical interaction not only involves viral proteins but also virus-encoded RNAs. This was well documented for Adenovirus, which produces a highly structured 160 nt viral RNA called VA-I RNA, that interacts with PKR and inhibits its activation (Price and Penman, 1972; Mathews and Shenk, 1991; for review, see Punga et al., 2020). Similar short transcripts named EBERs (EBER-1 and EBER-2), transcribed lately during Epstein-Barr virus infection, were shown to bind to and inhibit PKR, thereby conferring resistance to IFN-induced apoptosis in Burkitt lymphoma cells (Greifenegger et al., 1998; Nanbo et al., 2002). EBERs and VA-I are extremely abundant viral transcripts. They were shown to compete for PKR binding and to bind PKR with high affinity ( $\mathrm{K}_{\mathrm{d}}$ ca. $0.3 \mathrm{nM}$; Sharp et al., 1993).

Tat-responsive region RNA (TAR) of human immunodeficiency virus $1(\mathrm{HIV}-1)$ is another viral RNA that shares the capacity to inhibit PKR activity (Gunnery et al., 1990). Interestingly, TAR RNA forms a $23 \mathrm{bp}$ hairpin that binds PKR monomers but cannot accommodate PKR dimers because PKR dimer binding requires a dsRNA stretch longer than $30 \mathrm{bp}$. TAR RNA can also self-associate, thus forming longer dsRNA molecules, which show the ability to activate PKR in vitro (Heinicke et al., 2009). Interestingly, increasing the concentration of dsRNA, even of long dsRNA species that have the capacity to activate PKR, leads to PKR inhibition, likely because PKR monomers are diluted out on separate dsRNA molecules and have therefore decreased ability to dimerize (Heinicke et al., 2009; Sunita et al., 2015).

VA-I RNA structure, examined by many biochemical approaches (see Punga et al., 2020), and more recently by small-angle X-ray scattering (SAXS; Launer-Felty et al., 2015) and X-ray crystallography (Hood et al., 2019), displays an elongated apical stem, a central domain, and a short terminal stem. The apical stem forms a highly stable $22 \mathrm{bp}$ helix allowing PKR binding and carrying several wobble nucleotide pairs, which surprisingly appear to tune down slightly the inhibitory activity of VA-I RNA (Hood et al., 2019). The central domain of VA-I, which contains a pseudoknot structure and a conserved tetranucleotide stem, is essential for PKR inhibition and presumably acts by preventing PKR dimerization (Launer-Felty et al., 2015; Dzananovic et al., 2017; Hood et al., 2019).

In conclusion, virus-encoded small RNAs appear to act by preventing PKR dimerization in two different ways: (i) through their abundance, they trap PKR monomers and decrease the chances of PKR dimerization on a single-dsRNA molecule; (ii) through their structure, they inhibit dimerization via a still-elusive mechanism.

\section{Interacting Viral Proteins}

Some viral proteins were shown to bind PKR through direct protein-protein interaction, thereby blocking PKR autophosphorylation, dimerization, or phosphorylation of eIF2 $\alpha$. Examples include the nucleoprotein $(\mathrm{N})$ of Respiratory syncytial virus (RSV; Groskreutz et al., 2010), Tat from HIV-1 (McMillan et al., 1995; Brand et al., 1997), and ORF57 from Kaposi's sarcoma-associated herpes virus (KSVH; Sharma et al., 2017). NS5A of hepatitis $\mathrm{C}$ was found to bind the dimerization domain of PKR in a two-hybrid screen and in transfected COS-1 cells (Gale et al., 1997, 1998). Although no evidence was provided that PKR is inhibited by NS5A during HCV infection (Dabo and Meurs, 2012), substituting NS5A for E3L in VACV showed PKR inhibition in infected cells (He et al., 2001). Some proteins inhibit PKR kinase activation by interacting with PKR as pseudosubstrates. Examples include the E2 envelope protein of hepatitis C virus (Taylor et al., 1999) and K3L of VACV (Davies et al., 1992).

Interestingly, a number of viral proteins were shown to bind both PKR and dsRNA. These include the NS1 protein of Influenza virus and the E3L protein of VACV referred to above, but also the Us11 protein from Herpes simplex 1 virus (HSV-1; Poppers et al., 2000; Cassady and Gross, 2002), the related early Sm protein of Epstein-Barr virus (EBV; Poppers et al., 2003) or the TRS1 protein produced by the human cytomegalovirus (CMV; Marshall et al., 2009). In the latter case, although TRS1 residues required for PKR and dsRNAs binding do not fully overlap, interaction with both substrates is required to achieve full PKR inhibition (Bierle et al., 2013). The VP35 protein encoded by filoviruses, such as Ebola and Marburg viruses, was also reported to interact with both dsRNA and PKR, through a C-terminal domain called IID. However, mutations in this domain that affect dsRNA binding do not affect PKR inhibition, suggesting that dsRNA binding by VP35 is not mandatory for PKR inhibition (Schumann et al., 2009).

\section{PKR Inhibition Through Cellular Interacting Proteins}

As introduced above, several host proteins were reported to regulate $\mathrm{PKR}$ in either a positive or a negative fashion.

TRBP, a PKR inhibitor, was discovered as protein binding to the TAR RNA sequence of HIV (Gatignol et al., 1991). TAR can also bind to and activate PKR. In HIV-infected cells, however, TRBP was shown to contribute to PKR inhibition although the precise mechanism of this inhibition is unclear (Sanghvi and Steel, 2011).

PACT can be targeted as a PKR evasion strategy. In addition to binding to dsRNA and PKR itself (Liao et al., 2021), the Orf virus (ORFV)-encoded protein OV20.0 was shown to interact with PACT, thereby blocking PACT-mediated PKR activation (Tseng et al., 2015). 
As referred to above, Us11 of HSV-1 uses its RNA-binding domain to interact with PKR kinase, leading to the prevention of eIF2 $\alpha$ phosphorylation. Us11 was also shown to interact with PACT, suggesting an indirect mechanism of PKR inhibition as above. It was, however, shown that Us11 interaction with PKR was more important than interaction with PACT for Us11-mediated PKR inhibition (Peters et al., 2002). The situation is very similar in the case of filovirus VP35 proteins. In addition to binding dsRNA and PKR, Marburg virus VP35 also interacts with PACT. PKR inhibition does, however, not seem to rely on direct binding to PACT because PKR inhibition by VP35 turned out to be cell type-dependent and was not restored by ectopic expression of PACT (Hume and Mühlberger, 2018).

Influenza virus is able to induce PKR inhibition through activation of DnaJ heat shock protein family (Hsp40) member C3, known as P58 ${ }^{\mathrm{IPK}}$, which is one of the cellular PKR inhibitors (Lee et al., 1994). P58 ${ }^{\mathrm{IPK}}$ forms a complex with other heat shock proteins (Hsp) Hsp40 and Hsp70 where it is not active. The nucleoprotein (NP) from Influenza A virus can associate with HSP40, thereby leading to the dissociation of $\mathrm{P} 58^{\mathrm{IPK}}$ from the chaperone complex. Free $\mathrm{P} 58^{\mathrm{IPK}}$ in turn acts to inhibit PKR (Polyak et al., 1996; Melville et al., 1999; Sharma et al., 2011).

\section{elF2 $\alpha$ Dephosphorylation}

Some viruses evolved to act downstream of the PKR pathway, by triggering the dephosphorylation of phospho-eIF2 $\alpha$.

IBV infection was shown to upregulate the transcription of GADD34, a co-factor of the PP1 phosphatase, which guides this phosphatase toward specific substrates including phosphoeIF2 $\alpha$, thereby preventing PKR-mediated translation inhibition (Wang et al., 2009).

Similarly, ICP34.5 protein of HSV-1 can substitute for GADD34 by complexing the PP1 phosphatase via its C-terminus and redirecting PP1 toward phospho-eIF2 $\alpha$ (He et al., 1998).

In the context of RSV, the nucleoprotein $(\mathrm{N})$ was found to recruit PP2, which in turn binds to eIF2 $\alpha$, causing its dephosphorylation and permitting viral spread (Groskreutz et al., 2010).

\section{Acting Downstream From elF2 $\alpha$}

Lately, it has been shown that another Bunyavirus, sandfly sicilian phlebovirus (SFSV), can indirectly escape the PKR response by acting on eIF2B, the guanine nucleotide exchange factor whose activity is prevented when bound to phosphoeIF2 $\alpha$. Data of Wuerth et al. suggest a model where the NSs protein of SFSV would bind the eIF2B-eIF2 complex (that includes eIF $2 \alpha$ ), thereby modifying the structure of the complex in such a way to restore eIF2B guanine nucleotide exchange activity despite eIF2 $\alpha$ Ser51 phosphorylation (Wuerth et al., 2020).

NS4A protein from Dengue virus (DENV) has been shown to evade the innate immune response by a different mechanism. The protein can bind eIF4I and supports DENV replication in the cells. Knockdown of eIF4I surprisingly decreased PKR and eIF $2 \alpha$ phosphorylation levels. This shows that the viral protein is able to limit PKR activation by sequestering a potential direct or indirect activator of PKR (Chen et al., 2015).

\section{Additional Mechanisms}

PKR desensitization: Through a still undefined mechanism, the leader (L) protein of Theiler's murine encephalomyelitis virus (TMEV) can act to prevent dsRNA recognition by PKR and inhibit stress granule formation although the $\mathrm{L}$ protein does not interact with dsRNA (Borghese and Michiels, 2011; Borghese et al., 2019).

Activation of PKR: in contrast to other viral proteins, p17 from ARV was shown to subvert the innate immune response by triggering PKR. In this case, activation of PKR contributed to triggering autophagy, which was found to increase virus replication (Chi et al., 2013, 2019). Other viruses take advantage of some extent of PKR activation. For instance, reoviruses which use the $\sigma 3$ dsRNA-binding protein to dampen PKR activation still benefit from some level of PKR activation to trigger protein synthesis shutoff (Smith et al., 2005). Similarly, HCV, which was reported to inhibit PKR through proteins NS5A and E2, was proposed to take advantage of some level of PKR activation to inhibit IFN mRNA translation while IRES-mediated translation of its own genome was not affected by eIF $2 \alpha$ phosphorylation (Arnaud et al., 2010; Kim et al., 2011).

\section{DISCUSSION}

\section{Acting Upstream or Downstream From the Pathway?}

At first glance, it would look more effective for viral proteins to act upstream from PKR activation, by shielding dsRNA. Indeed, in addition to inhibiting PKR activation, such proteins are expected to prevent equally the activation of the other innate immune response pathways that depend on dsRNA recognition, such as the MDA5/MAVS pathway leading to IFN expression, or the oligoadenylate synthetase/RNaseL pathway leading to RNA degradation and IFN response amplification (Drappier and Michiels, 2015; Tan et al., 2018).

It is therefore unclear why some viruses evolved to act on downstream steps, for instance by triggering specific PKR degradation. It may be considered that a too broad inhibition of innate immunity would be detrimental to the virus because uncontrolled viral spread may lead to enhanced virus detection by the immune response or to premature death of the host, thus decreasing the chances of host-to-host transmission. Viruses possibly evolved to target specific arms of the innate immune response according to the cell type that they infect.

It is noteworthy that, acting at the other end of the pathway, downstream from eIF $2 \alpha$ phosphorylation leads to other effects. Indeed, eIF $2 \alpha$ phosphorylation is the convergence point of distinct arms of the ISR, involving the four eIF2 $\alpha$ kinases: PKR, PERK, GCN2, and HRI (Taniuchi et al., 2016). Thus, viruses, such as IBV, which promote eIF2 $\alpha$ dephosphorylation by hijacking cellular phosphatases (Wang et al., 2009) or viruses, such as SFSV, which prevent eIF2B inhibition (Wuerth et al., 2020) not only escape PKR but also PERK activity. Escaping PERK activity is likely important for such enveloped viruses, which may trigger endoplasmic reticulum stress due to massive 
viral glycoprotein exportation. Note that GCN2 and to a lesser extent HRI were also suggested to play antiviral roles and to be targeted by viruses (Liu et al., 2020).

\section{Targeting Multiple Steps of the Pathway}

Some viruses devote more than one coding region of their genome to the inhibition of the PKR pathway.

K3L (Davies et al., 1992; Carroll et al., 1993) and E3L (Beattie et al., 1995; Romano et al., 1998) proteins from VACV both contribute to PKR phosphorylation inhibition: the former, by binding to PKR, acts as a PKR pseudosubstrate to inhibit phosphorylation of eIF $2 \alpha$, while the latter acts by interacting with both dsRNA and PKR to mediate the inhibition.

In the case of Infectious bronchitis virus (IBV), three mechanisms have been proposed to be involved in the inhibition of the PKR pathway. First, the nsp15 endonuclease encoded by this virus was proposed to trigger the degradation of PKR-activating RNA molecules in infected cells (Gao et al., 2021; Zhao et al., 2021). Next, infection by IBV was reported to lead to a transcriptional upregulation of the gene coding GADD34, thus enhancing PP1-mediated dephosphorylation of eIF2 $\alpha$ (Wang et al., 2009). In the same work, it was shown that IBV Nsp2 displayed a weak PKR antagonist activity, although the mechanism of PKR inhibition by this protein was not elucidated (Wang et al., 2009). In this case, targeting multiple players in the PKR pathway can not only increase the potency of PKR inhibition but can also help to evade other innate immunity pathways.

\section{Future Prospects}

More and more studies emphasize the possibility to regulate PKR activation through posttranslational modifications, such as SUMOylation, ISGylation, ubiquitination, and phosphorylation. As reported above, NSs proteins of bunyaviruses like RVFV can assemble an ubiquitin ligase complex, which targets PKR for proteasomal degradation (Mudhasani et al., 2016).

In contrast, although ISGylation and SUMOylation were shown to modulate PKR activity (Okumura et al., 2013; de la CruzHerrera et al., 2014; Maarifi et al., 2018), no viral protein has been identified yet that would trigger PKR posttranslational modification by the attachment of ISG15 or SUMO. It is likely that such proteins exist but remain to be identified.

\section{REFERENCES}

Anderson, P., and Kedersha, N. (2008). Stress granules: the Tao of RNA triage. Trends Biochem. Sci. 33, 141-150. doi: 10.1016/j.tibs.2007.12.003

Arnaud, N., Dabo, S., Maillard, P., Budkowska, A., Kalliampakou, K. I., Mavromara, P., et al. (2010). Hepatitis C virus controls interferon production through PKR activation. PLoS One 5:e10575. doi: 10.1371/journal.pone.0010575

Beattie, E., Paoletti, E., and Tartaglia, J. (1995). Distinct patterns of IFN sensitivity observed in cells infected with vaccinia K3L- and E3L- mutant viruses. Virology 210, 254-263. doi: 10.1006/viro.1995.1342

Bennett, R. L., Pan, Y., Christian, J., Hui, T., and May, W. S. Jr. (2012). The RAX/PACT-PKR stress response pathway promotes p53 sumoylation and activation, leading to $\mathrm{G}_{1}$ arrest. Cell Cycle 11, 407-417. doi: 10.4161/ cc.11.2.18999
Phosphorylation is another posttranslational modification involved in activation and fine tuning of PKR activity. Although viruses are well known to trigger extensive signal transduction cascades through phosphorylation by virus-encoded and cellular kinases, to the best of our knowledge, no viral PKR escape mechanism has been deciphered that would be based on inhibitory phosphorylation of PKR residues. The recent development of high-throughput phosphoproteomic methods might hopefully lead to new discoveries in this field.

Although this review focuses on the antiviral activity of the PKR-eIF2 $\alpha$ axis and viral countermeasures, it is important to keep in mind that PKR activity is not limited to translation inhibition. PKR is also connected to other diverse and critical pathways, including mitosis and apoptosis control by p53, inflammation control through NFKB activation (Bennett et al., 2012), IFN production (Schulz et al., 2010), and even neuronal homeostasis (Gal-Ben-Ari et al., 2018). The involvement of PKR in these pathways suggests many alternative ways by which PKR might control viral infection and influence virus evolution.

\section{AUTHOR CONTRIBUTIONS}

TC wrote the first draft of the manuscript. TC and TM wrote sections of the manuscript. All authors contributed to the article and approved the submitted version.

\section{FUNDING}

TC was the recipient of an Aspirant fellowship of the FNRS. Work was supported by the EOS joint programme of Fonds de la recherche scientifique-FNRS and Fonds wetenschapellijk onderzoek-Vlaanderen-FWO (EOS ID: 30981113) by national lotery players and Actions de Recherche concertée (ARC).

\section{ACKNOWLEDGMENTS}

We are grateful to Fanny Wavreil and Stéphane Messe who provide high-quality technical assistance in the laboratory work about PKR.

Bierle, C. J., Semmens, K. M., and Geballe, A. P. (2013). Double-stranded RNA binding by the human cytomegalovirus PKR antagonist TRS1. Virology 442, 28-37. doi: 10.1016/j.virol.2013.03.024

Borghese, F., and Michiels, T. (2011). The leader protein of cardioviruses inhibits stress granule assembly. J. Virol. 85, 9614-9622. doi: 10.1128/JVI.00480-11

Borghese, F., Sorgeloos, F., Cesaro, T., and Michiels, T. (2019). The leader protein of Theiler's virus prevents the activation of PKR by dsRNA. J. Virol. 93:e01010-19. doi: 10.1128/JVI.01010-19

Brand, S. R., Kobayashi, R., and Mathews, M. B. (1997). The tat protein of human immunodeficiency virus type 1 is a substrate and inhibitor of the interferon-induced, virally activated protein kinase, PKR. J. Biol. Chem. 272, 8388-8395. doi: 10.1074/jbc.272.13.8388

Carroll, K., Elroy-Stein, O., Moss, B., and Jagus, R. (1993). Recombinant vaccinia virus $\mathrm{K} 3 \mathrm{~L}$ gene product prevents activation of double-stranded RNA-dependent, 
initiation factor 2 alpha-specific protein kinase. J. Biol. Chem. 268, 12837-12842. doi: 10.1016/S0021-9258(18)31463-7

Cassady, K. A., and Gross, M. (2002). The herpes simplex virus type $1 \mathrm{U}(\mathrm{S}) 11$ protein interacts with protein kinase $\mathrm{R}$ in infected cells and requires a 30-amino-acid sequence adjacent to a kinase substrate domain. J. Virol. 76, 2029-2035. doi: 10.1128/jvi.76.5.2029-2035.2002

Cesaro, T., Hayashi, Y., Borghese, F., Vertommen, D., Wavreil, F., and Michiels, T. (2021). PKR activity modulation by phosphomimetic mutations of serine residues located three aminoacids upstream of double-stranded RNA binding motifs. Sci. Rep. 11:9188. doi: 10.1038/s41598-021-88610-z

Chen, X., Xia, J., Zhao, Q., Wang, Y., Liu, J., Feng, L., et al. (2015). Eukaryotic initiation factor 4AI interacts with NS4A of dengue virus and plays an antiviral role. Biochem. Biophys. Res. Commun. 461, 148-153. doi: 10.1016/j. bbrc.2015.04.004

Chi, P. I., Huang, W. R., Lai, I. H., Cheng, C. Y., and Liu, H. J. (2013). The p17 nonstructural protein of avian reovirus triggers autophagy enhancing virus replication via activation of phosphatase and tensin deleted on chromosome 10 (PTEN) and AMP-activated protein kinase (AMPK), as well as dsRNA-dependent protein kinase (PKR)/eIF2alpha signaling pathways. J. Biol. Chem. 288, 3571-3584. doi: 10.1074/jbc.M112.390245

Chi, P. I., Huang, W. R., Lai, I. H., Cheng, C. Y., and Liu, H. J. (2019). Correction: The $\mathrm{p} 17$ nonstructural protein of avian reovirus triggers autophagy enhancing virus replication via activation of phosphatase and tensin deleted on chromosome 10 (PTEN) and AMP-activated protein kinase (AMPK), as well as dsRNA-dependent protein kinase (PKR)/eIF2 alpha signaling pathways. J. Biol. Chem. 294:11676. doi: 10.1074/jbc.AAC119.010041

Chiang, J. J., Sparrer, K. M. J., van Gent, M., Lassig, C., Huang, T., Osterrieder, N., et al. (2018). Viral unmasking of cellular 5S rRNA pseudogene transcripts induces RIG-I-mediated immunity. Nat. Immunol. 19, 53-62. doi: 10.1038/ s41590-017-0005-y

Chung, H., Calis, J. J. A., Wu, X., Sun, T., Yu, Y., Sarbanes, S. L., et al. (2018). Human ADAR1 prevents endogenous RNA from triggering translational shutdown. Cell 172, 811.e14-824.e14. doi: 10.1016/j.cell.2017.12.038

Colpitts, C. C., Ridewood, S., Schneiderman, B., Warne, J., Tabata, K., Ng, C. F., et al. (2020). Hepatitis C virus exploits cyclophilin A to evade PKR. elife 9:e52237. doi: 10.7554/eLife.52237

Cuddihy, A. R., Wong, A. H., Tam, N. W., Li, S., and Koromilas, A. E. (1999). The double-stranded RNA activated protein kinase PKR physically associates with the tumor suppressor p53 protein and phosphorylates human p53 on serine 392 in vitro. Oncogene 18, 2690-2702. doi: 10.1038/sj.onc.1202620

Dabo, S., Maillard, P., Collados Rodriguez, M., Hansen, M. D., Mazouz, S., Bigot, D. J., et al. (2017). Inhibition of the inflammatory response to stress by targeting interaction between PKR and its cellular activator PACT. Sci. Rep. 7:16129. doi: 10.1038/s41598-017-16089-8

Dabo, S., and Meurs, E. F. (2012). dsRNA-dependent protein kinase PKR and its role in stress, signaling and HCV infection. Viruses 4, 2598-2635. doi: 10.3390/v4112598

Dauber, B., Pelletier, J., and Smiley, J. R. (2011). The herpes simplex virus 1 vhs protein enhances translation of viral true late mRNAs and virus production in a cell type-dependent manner. J. Virol. 85, 5363-5373. doi: 10.1128/ jvi.00115-11

Dauber, B., Schneider, J., and Wolff, T. (2006). Double-stranded RNA binding of influenza B virus nonstructural NS1 protein inhibits protein kinase R but is not essential to antagonize production of alpha/beta interferon. $J$. Virol. 80, 11667-11677. doi: 10.1128/JVI.01142-06

Dauber, B., and Wolff, T. (2009). Activation of the antiviral kinase PKR and viral countermeasures. Viruses 1, 523-544. doi: 10.3390/v1030523

Davies, M. V., Chang, H. W., Jacobs, B. L., and Kaufman, R. J. (1993). The E3L and $\mathrm{K} 3 \mathrm{~L}$ vaccinia virus gene products stimulate translation through inhibition of the double-stranded RNA-dependent protein kinase by different mechanisms. J. Virol. 67, 1688-1692. doi: 10.1128/ jvi.67.3.1688-1692.1993

Davies, M. V., Elroy-Stein, O., Jagus, R., Moss, B., and Kaufman, R. J. (1992). The vaccinia virus $\mathrm{K} 3 \mathrm{~L}$ gene product potentiates translation by inhibiting double-stranded-RNA-activated protein kinase and phosphorylation of the alpha subunit of eukaryotic initiation factor 2. J. Virol. 66, 1943-1950. doi: 10.1128/jvi.66.4.1943-1950.1992

de la Cruz-Herrera, C. F., Campagna, M., García, M. A., Marcos-Villar, L., Lang, V., Baz-Martínez, M., et al. (2014). Activation of the double-stranded
RNA-dependent protein kinase PKR by small ubiquitin-like modifier (SUMO). J. Biol. Chem. 289, 26357-26367. doi: 10.1074/jbc.M114.560961

Dey, M., Cao, C., Dar, A. C., Tamura, T., Ozato, K., Sicheri, F., et al. (2005). Mechanistic link between PKR dimerization, autophosphorylation, and eIF2alpha substrate recognition. Cell 122, 901-913. doi: 10.1016/j.cell.2005.06.041

Drappier, M., and Michiels, T. (2015). Inhibition of the OAS/RNase L pathway by viruses. Curr. Opin. Virol. 15, 19-26. doi: 10.1016/j.coviro.2015.07.002

Dzananovic, E., Chojnowski, G., Deo, S., Booy, E. P., Padilla-Meier, P., McEleney, K., et al. (2017). Impact of the structural integrity of the three-way junction of adenovirus VAI RNA on PKR inhibition. PLoS One 12:e186849. doi: 10.1371/journal.pone.0186849

Dzananovic, E., McKenna, S. A., and Patel, T. R. (2018). Viral proteins targeting host protein kinase $\mathrm{R}$ to evade an innate immune response: a mini review. Biotechnol. Genet. Eng. Rev. 34, 33-59. doi: 10.1080/02648725.2018.1467151

Esteban, M., Garcia, M. A., Domingo-Gil, E., Arroyo, J., Nombela, C., and Rivas, C. (2003). The latency protein LANA2 from Kaposi's sarcoma-associated herpesvirus inhibits apoptosis induced by dsRNA-activated protein kinase but not RNase L activation. J. Gen. Virol. 84, 1463-1470. doi: 10.1099/ vir.0.19014-0

Friedman, R. M., Metz, D. H., Esteban, R. M., Tovell, D. R., Ball, L. A., and Kerr, I. M. (1972). Mechanism of interferon action: inhibition of viral messenger ribonucleic acid translation in L-cell extracts. J. Virol. 10, 1184-1198. doi: 10.1128/jvi.10.6.1184-1198.1972

Gal-Ben-Ari, S., Barrera, I., Ehrlich, M., and Rosenblum, K. (2018). PKR: A kinase to remember. Front. Mol. Neurosci. 11:480. doi: 10.3389/fnmol.2018.00480

Gale, M. Jr., Blakely, C. M., Kwieciszewski, B., Tan, S. L., Dossett, M., Tang, N. M., et al. (1998). Control of PKR protein kinase by hepatitis C virus nonstructural 5A protein: molecular mechanisms of kinase regulation. Mol. Cell. Biol. 18, 5208-5218. doi: 10.1128/MCB.18.9.5208

Gale, M. J. Jr., Korth, M. J., Tang, N. M., Tan, S. L., Hopkins, D. A., Dever, T. E., et al. (1997). Evidence that hepatitis C virus resistance to interferon is mediated through repression of the PKR protein kinase by the nonstructural 5A protein. Virology 230, 217-227. doi: 10.1006/viro.1997.8493

Gao, B., Gong, X., Fang, S., Weng, W., Wang, H., Chu, H., et al. (2021). Inhibition of anti-viral stress granule formation by coronavirus endoribonuclease nsp15 ensures efficient virus replication. PLoS Pathog. 17:e1008690. doi: 10.1371/journal.ppat.1008690

Garcia, M. A., Gil, J., Ventoso, I., Guerra, S., Domingo, E., Rivas, C., et al. (2006). Impact of protein kinase PKR in cell biology: from antiviral to antiproliferative action. Microbiol. Mol. Biol. Rev. 70, 1032-1060. doi: 10.1128/ MMBR.00027-06

Garcia, M. A., Meurs, E. F., and Esteban, M. (2007). The dsRNA protein kinase PKR: virus and cell control. Biochimie 89, 799-811. doi: 10.1016/j. biochi.2007.03.001

Gatignol, A., Buckler-White, A., Berkhout, B., and Jeang, K. T. (1991). Characterization of a human TAR RNA-binding protein that activates the HIV-1 LTR. Science 251, 1597-1600. doi: 10.1126/science.2011739

Golec, E., Lind, L., Qayyum, M., Blom, A. M., and King, B. C. (2019). The noncoding RNA nc886 regulates PKR signaling and cytokine production in human cells. J. Immunol. 202, 131-141. doi: 10.4049/jimmunol.1701234

Gonzalez-Lopez, C., Martinez-Costas, J., Esteban, M., and Benavente, J. (2003). Evidence that avian reovirus sigmaA protein is an inhibitor of the doublestranded RNA-dependent protein kinase. J. Gen. Virol. 84, 1629-1639. doi: 10.1099/vir.0.19004-0

Goodman, D. E., Pretto, C. D., Krepostman, T. A., Carnahan, K. E., and Spindler, K. R. (2019). Enhanced replication of mouse adenovirus type 1 following virus-induced degradation of protein kinase R (PKR). MBio 10:e0668-19. doi: 10.1128/mBio.00668-19

Greifenegger, N., Jager, M., Kunz-Schughart, L. A., Wolf, H., and Schwarzmann, F. (1998). Epstein-Barr virus small RNA (EBER) genes: differential regulation during lytic viral replication. J. Virol. 72, 9323-9328. doi: 10.1128/ JVI.72.11.9323-9328.1998

Groskreutz, D. J., Babor, E. C., Monick, M. M., Varga, S. M., and Hunninghake, G. W. (2010). Respiratory syncytial virus limits alpha subunit of eukaryotic translation initiation factor 2 (eIF2alpha) phosphorylation to maintain translation and viral replication. J. Biol. Chem. 285, 24023-24031. doi: 10.1074/jbc.M109.077321

Gunnery, S., Rice, A. P., Robertson, H. D., and Mathews, M. B. (1990). Tatresponsive region RNA of human immunodeficiency virus 1 can prevent 
activation of the double-stranded-RNA-activated protein kinase. Proc. Natl. Acad. Sci. U. S. A. 87, 8687-8691. doi: 10.1073/pnas.87.22.8687

Guo, Y., Hinchman, M. M., Lewandrowski, M., Cross, S. T., Sutherland, D. M., Welsh, O. L., et al. (2021). The multi-functional reovirus sigma3 protein is a virulence factor that suppresses stress granule formation and is associated with myocardial injury. PLoS Pathog. 17:e1009494. doi: 10.1371/journal.ppat.1009494

Gusho, E., Baskar, D., and Banerjee, S. (2020). New advances in our understanding of the "unique" RNase L in host pathogen interaction and immune signaling. Cytokine 133:153847. doi: 10.1016/j.cyto.2016.08.009

He, B., Gross, M., and Roizman, B. (1998). The gamma134.5 protein of herpes simplex virus 1 has the structural and functional attributes of a protein phosphatase 1 regulatory subunit and is present in a high molecular weight complex with the enzyme in infected cells. J. Biol. Chem. 273, 20737-20743. doi: $10.1074 /$ jbc.273.33.20737

He, Y., Tan, S. L., Tareen, S. U., Vijaysri, S., Langland, J. O., Jacobs, B. L., et al. (2001). Regulation of mRNA translation and cellular signaling by hepatitis C virus nonstructural protein NS5A. J. Virol. 75, 5090-5098. doi: 10.1128/JVI.75.11.5090-5098.2001

Heinicke, L. A., Wong, C. J., Lary, J., Nallagatla, S. R., Diegelman-Parente, A., Zheng, X., et al. (2009). RNA dimerization promotes PKR dimerization and activation. J. Mol. Biol. 390, 319-338. doi: 10.1016/j.jmb.2009.05.005

Hood, I. V., Gordon, J. M., Bou-Nader, C., Henderson, F. E., Bahmanjah, S., and Zhang, J. (2019). Crystal structure of an adenovirus virus-associated RNA. Nat. Commun. 10:2871. doi: 10.1038/s41467-019-10752-6

Hu, Z., Wang, Y., Tang, Q., Yang, X., Qin, Y., and Chen, M. (2018). Inclusion bodies of human parainfluenza virus type 3 inhibit antiviral stress granule formation by shielding viral RNAs. PLoS Pathog. 14:e1006948. doi: 10.1371/ journal.ppat. 1006948

Huang, X., Hutchins, B., and Patel, R. C. (2002). The C-terminal, third conserved motif of the protein activator PACT plays an essential role in the activation of double-stranded-RNA-dependent protein kinase (PKR). Biochem. J. 366, 175-186. doi: $10.1042 /$ bj20020204

Hume, A., and Mühlberger, E. (2018). Marburg virus viral protein 35 inhibits protein kinase $\mathrm{R}$ activation in a cell type-specific manner. J. Infect. Dis. 218(Suppl. 5), S403-S408. doi: 10.1093/infdis/jiy473

Ikegami, T., Narayanan, K., Won, S., Kamitani, W., Peters, C. J., and Makino, S. (2009). Dual functions of Rift Valley fever virus NSs protein: inhibition of host mRNA transcription and post-transcriptional downregulation of protein kinase PKR. Ann. N. Y. Acad. Sci. 1171(Suppl. 1), E75-E85. doi: 10.1111/j. 1749-6632.2009.05054.x

Jacobs, B. L., and Langland, J. O. (1998). Reovirus sigma 3 protein: dsRNA binding and inhibition of RNA-activated protein kinase. Curr. Top. Microbiol. Immunol. 233, 185-196. doi: 10.1007/978-3-642-72092-5_9

Jeffrey, I. W., Kadereit, S., Meurs, E. F., Metzger, T., Bachmann, M., Schwemmle, M., et al. (1995). Nuclear localization of the interferon-inducible protein kinase PKR in human cells and transfected mouse cells. Exp. Cell Res. 218, 17-27. doi: $10.1006 /$ excr.1995.1126

Jeon, S. H., Lee, K., Lee, K. S., Kunkeaw, N., Johnson, B. H., Holthauzen, L. M., et al. (2012). Characterization of the direct physical interaction of nc886, a cellular non-coding RNA, and PKR. FEBS Lett. 586, 3477-3484. doi: 10.1016/j.febslet.2012.07.076

Kalveram, B., and Ikegami, T. (2013). Toscana virus NSs protein promotes degradation of double-stranded RNA-dependent protein kinase. J. Virol. 87, 3710-3718. doi: 10.1128/JVI.02506-12

Kalveram, B., Lihoradova, O., Indran, S. V., Lokugamage, N., Head, J. A., and Ikegami, T. (2013). Rift Valley fever virus NSs inhibits host transcription independently of the degradation of dsRNA-dependent protein kinase PKR. Virology 435, 415-424. doi: 10.1016/j.virol.2012.09.031

Kawakubo, K., Kuhen, K. L., Vessey, J. W., George, C. X., and Samuel, C. E. (1999). Alternative splice variants of the human PKR protein kinase possessing different 5 '-untranslated regions: expression in untreated and interferontreated cells and translational activity. Virology 264, 106-114. doi: 10.1006/ viro.1999.9995

Kerr, I. M., Brown, R. E., and Hovanessian, A. G. (1977). Nature of inhibitor of cell-free protein synthesis formed in response to interferon and doublestranded RNA. Nature 268, 540-542. doi: 10.1038/268540a0

Kim, J. H., Park, S. M., Park, J. H., Keum, S. J., and Jang, S. K. (2011). eIF2A mediates translation of hepatitis $\mathrm{C}$ viral mRNA under stress conditions. EMBO J. 30, 2454-2464. doi: 10.1038/emboj.2011.146
Kuhen, K. L., and Samuel, C. E. (1997). Isolation of the interferon-inducible RNA-dependent protein kinase Pkr promoter and identification of a novel DNA element within the 5'-flanking region of human and mouse Pkr genes. Virology 227, 119-130. doi: 10.1006/viro.1996.8306

Langereis, M. A., Feng, Q., and van Kuppeveld, F. J. (2013). MDA5 localizes to stress granules, but this localization is not required for the induction of type I interferon. J. Virol. 87, 6314-6325. doi: 10.1128/JVI.03213-12

Launer-Felty, K., Wong, C. J., and Cole, J. L. (2015). Structural analysis of adenovirus VAI RNA defines the mechanism of inhibition of PKR. Biophys. J. 108, 748-757. doi: 10.1016/j.bpj.2014.12.014

Lee, K., Kunkeaw, N., Jeon, S. H., Lee, I., Johnson, B. H., Kang, G. Y., et al. (2011). Precursor miR-886, a novel noncoding RNA repressed in cancer, associates with PKR and modulates its activity. RNA 17, 1076-1089. doi: $10.1261 /$ rna.2701111

Lee, T. G., Tang, N., Thompson, S., Miller, J., and Katze, M. G. (1994). The 58,000-Dalton cellular inhibitor of the interferon-induced double-stranded RNA-activated protein kinase (PKR) is a member of the tetratricopeptide repeat family of proteins. Mol. Cell. Biol. 14, 2331-2342. doi: 10.1128/ mcb.14.4.2331

Li, C., Zhu, Z., Du, X., Cao, W., Yang, F., Zhang, X., et al. (2017). Foot-andmouth disease virus induces lysosomal degradation of host protein kinase PKR by 3C proteinase to facilitate virus replication. Virology 509, 222-231. doi: $10.1016 /$ j.virol.2017.06.023

Li, S., and Koromilas, A. E. (2001). Dominant negative function by an alternatively spliced form of the interferon-inducible protein kinase PKR. J. Biol. Chem. 276, 13881-13890. doi: 10.1074/jbc.M008140200

Li, Z., Wolff, K. C., and Samuel, C. E. (2010). RNA adenosine deaminase ADAR1 deficiency leads to increased activation of protein kinase PKR and reduced vesicular stomatitis virus growth following interferon treatment Virology 396, 316-322. doi: 10.1016/j.virol.2009.10.026

Liao, G. R., Tseng, Y. Y., Tseng, C. Y., Huang, Y. P., Tsai, C. H., Liu, H. P., et al. (2021). K160 in the RNA-binding domain of the orf virus virulence factor OV20.0 is critical for its functions in counteracting host antiviral defense. FEBS Lett. 595, 1721-1733. doi: 10.1002/1873-3468.14099

Liu, C. X., Li, X., Nan, F., Jiang, S., Gao, X., Guo, S. K., et al. (2019). Structure and degradation of circular RNAs regulate PKR activation in innate immunity. Cell 177:e821. doi: 10.1016/j.cell.2019.03.046

Liu, Y., Wang, M., Cheng, A., Yang, Q., Wu, Y., Jia, R., et al. (2020). The role of host eIF2alpha in viral infection. Virol. J. 17:112. doi: 10.1186/ s12985-020-01362-6

Maarifi, G., El Asmi, F., Maroui, M. A., Dianoux, L., and Chelbi-Alix, M. K. (2018). Differential effects of SUMO1 and SUMO3 on PKR activation and stability. Sci. Rep. 8:1277. doi: 10.1038/s41598-018-19683-6

Marshall, E. E., Bierle, C. J., Brune, W., and Geballe, A. P. (2009). Essential role for either TRS1 or IRS1 in human cytomegalovirus replication. J. Virol. 83, 4112-4120. doi: 10.1128/JVI.02489-08

Mathews, M. B., and Shenk, T. (1991). Adenovirus virus-associated RNA and translation control. J. Virol. 65, 5657-5662. doi: 10.1128/jvi.65.11.5657-5662.1991

McCormick, C., and Khaperskyy, D. A. (2017). Translation inhibition and stress granules in the antiviral immune response. Nat. Rev. Immunol. 17, 647-660. doi: $10.1038 /$ nri.2017.63

McKenna, S. A., Lindhout, D. A., Shimoike, T., Aitken, C. E., and Puglisi, J. D. (2007). Viral dsRNA inhibitors prevent self-association and autophosphorylation of PKR. J. Mol. Biol. 372, 103-113. doi: 10.1016/j.jmb.2007.06.028

McMillan, N. A., Chun, R. F., Siderovski, D. P., Galabru, J., Toone, W. M., Samuel, C. E., et al. (1995). HIV-1 tat directly interacts with the interferoninduced, double-stranded RNA-dependent kinase, PKR. Virology 213, 413-424. doi: $10.1006 /$ viro.1995.0014

Melville, M. W., Tan, S. L., Wambach, M., Song, J., Morimoto, R. I., and Katze, M. G. (1999). The cellular inhibitor of the PKR protein kinase, P58(IPK), is an influenza virus-activated co-chaperone that modulates heat shock protein 70 activity. J. Biol. Chem. 274, 3797-3803. doi: 10.1074/ jbc.274.6.3797

Meurs, E., Chong, K., Galabru, J., Thomas, N. S., Kerr, I. M., Williams, B. R., et al. (1990). Molecular cloning and characterization of the human doublestranded RNA-activated protein kinase induced by interferon. Cell 62, 379-390. doi: 10.1016/0092-8674(90)90374-N

Min, J. Y., Li, S., Sen, G. C., and Krug, R. M. (2007). A site on the influenza A virus NS1 protein mediates both inhibition of PKR activation and temporal 
regulation of viral RNA synthesis. Virology 363, 236-243. doi: 10.1016/j. virol.2007.01.038

Mudhasani, R., Tran, J. P., Retterer, C., Kota, K. P., Whitehouse, C. A., and Bavari, S. (2016). Protein kinase R degradation is essential for Rift Valley fever virus infection and is regulated by SKP1-CUL1-F-box (SCF)FBXW11NSs E3 ligase. PLoS Pathog. 12:e1005437. doi: 10.1371/journal.ppat.1005437

Nanbo, A., Inoue, K., Adachi-Takasawa, K., and Takada, K. (2002). EpsteinBarr virus RNA confers resistance to interferon-alpha-induced apoptosis in Burkitt's lymphoma. EMBO J. 21, 954-965. doi: 10.1093/emboj/21.5.954

Nanduri, S., Rahman, F., Williams, B. R., and Qin, J. (2000). A dynamically tuned double-stranded RNA binding mechanism for the activation of antiviral kinase PKR. EMBO J. 19, 5567-5574. doi: 10.1093/emboj/19.20.5567

Okonski, K. M., and Samuel, C. E. (2013). Stress granule formation induced by measles virus is protein kinase PKR dependent and impaired by RNA adenosine deaminase ADAR1. J. Virol. 87, 756-766. doi: 10.1128/jvi.02270-12

Okumura, F., Okumura, A. J., Uematsu, K., Hatakeyama, S., Zhang, D. E., and Kamura, T. (2013). Activation of double-stranded RNA-activated protein kinase (PKR) by interferon-stimulated gene 15 (ISG15) modification downregulates protein translation. J. Biol. Chem. 288, 2839-2847. doi: 10.1074/ jbc.M112.401851

Onomoto, K., Yoneyama, M., Fung, G., Kato, H., and Fujita, T. (2014). Antiviral innate immunity and stress granule responses. Trends Immunol. 35, 420-428. doi: $10.1016 /$ j.it.2014.07.006

Pakos-Zebrucka, K., Koryga, I., Mnich, K., Ljujic, M., Samali, A., and Gorman, A. M. (2016). The integrated stress response. EMBO Rep. 17, 1374-1395. doi: 10.15252/embr.201642195

Park, H., Davies, M. V., Langland, J. O., Chang, H. W., Nam, Y. S., Tartaglia, J., et al. (1994). TAR RNA-binding protein is an inhibitor of the interferoninduced protein kinase PKR. Proc. Natl. Acad. Sci. U. S. A. 91, 4713-4717. doi: 10.1073/pnas.91.11.4713

Peters, G. A., Khoo, D., Mohr, I., and Sen, G. C. (2002). Inhibition of PACTmediated activation of PKR by the herpes simplex virus type 1 Us11 protein. J. Virol. 76, 11054-11064. doi: 10.1128/jvi.76.21.11054-11064.2002

Polyak, S. J., Tang, N., Wambach, M., Barber, G. N., and Katze, M. G. (1996). The P58 cellular inhibitor complexes with the interferon-induced, doublestranded RNA-dependent protein kinase, PKR, to regulate its autophosphorylation and activity. J. Biol. Chem. 271, 1702-1707. doi: 10.1074/ jbc.271.3.1702

Poppers, J., Mulvey, M., Khoo, D., and Mohr, I. (2000). Inhibition of PKR activation by the proline-rich RNA binding domain of the herpes simplex virus type 1 Us11 protein. J. Virol. 74, 11215-11221. doi: 10.1128/jvi.74.23.11215-11221.2000

Poppers, J., Mulvey, M., Perez, C., Khoo, D., and Mohr, I. (2003). Identification of a lytic-cycle Epstein-Barr virus gene product that can regulate PKR activation. J. Virol. 77, 228-236. doi: 10.1128/jvi.77.1.228-236.2003

Price, R., and Penman, S. (1972). A distinct RNA polymerase activity, synthesizing 5-5 s, $5 \mathrm{~s}$ and $4 \mathrm{~s}$ RNA in nuclei from adenovirus 2-infected HeLa cells. J. Mol. Biol. 70, 435-450. doi: 10.1016/0022-2836(72)90551-7

Punga, T., Darweesh, M., and Akusjarvi, G. (2020). Synthesis, structure, and function of human adenovirus small non-coding RNAs. Viruses 12:1182. doi: $10.3390 / \mathrm{v} 12101182$

Rabouw, H. H., Langereis, M. A., Knaap, R. C., Dalebout, T. J., Canton, J., Sola, I., et al. (2016). Middle East respiratory coronavirus accessory protein 4a inhibits PKR-mediated antiviral stress responses. PLoS Pathog. 12:e1005982. doi: 10.1371/journal.ppat.1005982

Reineke, L. C., Kedersha, N., Langereis, M. A., van Kuppeveld, F. J., and Lloyd, R. E. (2015). Stress granules regulate double-stranded RNA-dependent protein kinase activation through a complex containing G3BP1 and Caprin1. MBio 6:e02486. doi: 10.1128/mBio.02486-14

Robertson, H. D., and Mathews, M. B. (1996). The regulation of the protein kinase PKR by RNA. Biochimie 78, 909-914. doi: 10.1016/ S0300-9084(97)86712-0

Romano, P. R., Zhang, F., Tan, S. L., Garcia-Barrio, M. T., Katze, M. G., Dever, T. E., et al. (1998). Inhibition of double-stranded RNA-dependent protein kinase PKR by vaccinia virus E3: role of complex formation and the E3 N-terminal domain. Mol. Cell. Biol. 18, 7304-7316. doi: 10.1128/ mcb.18.12.7304

Saeed, M., Kapell, S., Hertz, N. T., Wu, X., Bell, K., Ashbrook, A. W., et al. (2020). Defining the proteolytic landscape during enterovirus infection. PLoS Pathog. 16:e1008927. doi: 10.1371/journal.ppat.1008927
Sanghvi, V. R., and Steel, L. F. (2011). The cellular TAR RNA binding protein, TRBP, promotes HIV-1 replication primarily by inhibiting the activation of double-stranded RNA-dependent kinase PKR. J. Virol. 85, 12614-12621. doi: $10.1128 /$ jvi.05240-11

Schmechel, S., Chute, M., Skinner, P., Anderson, R., and Schiff, L. (1997). Preferential translation of reovirus mRNA by a sigma3-dependent mechanism. Virology 232, 62-73. doi: 10.1006/viro.1997.8531

Schulz, O., Pichlmair, A., Rehwinkel, J., Rogers, N. C., Scheuner, D., Kato, H., et al. (2010). Protein kinase $\mathrm{R}$ contributes to immunity against specific viruses by regulating interferon mRNA integrity. Cell Host Microbe 7, 354-361. doi: $10.1016 /$ j.chom.2010.04.007

Schumann, M., Gantke, T., and Muhlberger, E. (2009). Ebola virus VP35 antagonizes PKR activity through its C-terminal interferon inhibitory domain. J. Virol. 83, 8993-8997. doi: 10.1128/JVI.00523-09

Sharma, N. R., Majerciak, V., Kruhlak, M. J., and Zheng, Z. M. (2017). KSHV inhibits stress granule formation by viral ORF57 blocking PKR activation PLoS Pathog. 13:e1006677. doi: 10.1371/journal.ppat.1006677

Sharma, K., Tripathi, S., Ranjan, P., Kumar, P., Garten, R., Deyde, V., et al. (2011). Influenza A virus nucleoprotein exploits Hsp40 to inhibit PKR activation. PLoS One 6:e20215. doi: 10.1371/journal.pone.0020215

Sharp, T. V., Schwemmle, M., Jeffrey, I., Laing, K., Mellor, H., Proud, C. G., et al. (1993). Comparative analysis of the regulation of the interferon-inducible protein kinase PKR by Epstein-Barr virus RNAs EBER-1 and EBER-2 and adenovirus VAI RNA. Nucleic Acids Res. 21, 4483-4490. doi: 10.1093/ nar/21.19.4483

Singh, M., Castillo, D., Patel, C. V., and Patel, R. C. (2011). Stress-induced phosphorylation of PACT reduces its interaction with TRBP and leads to PKR activation. Biochemistry 50, 4550-4560. doi: 10.1021/bi200104h

Smith, J. A., Schmechel, S. C., Williams, B. R., Silverman, R. H., and Schiff, L. A. (2005). Involvement of the interferon-regulated antiviral proteins PKR and RNase L in reovirus-induced shutoff of cellular translation. J. Virol. 79, 2240-2250. doi: 10.1128/JVI.79.4.2240-2250.2005

Spurgeon, M. E., and Ornelles, D. A. (2009). The adenovirus E1B 55-kilodalton and $\mathrm{E} 4$ open reading frame 6 proteins limit phosphorylation of eIF2alpha during the late phase of infection. J. Virol. 83, 9970-9982. doi: 10.1128/ JVI.01113-09

Sudha, G., Yamunadevi, S., Tyagi, N., Das, S., and Srinivasan, N. (2012). Structural and molecular basis of interaction of HCV non-structural protein 5A with human casein kinase lalpha and PKR. BMC Struct. Biol. 12:28. doi: 10.1186/1472-6807-12-28

Sudhakar, A., Ramachandran, A., Ghosh, S., Hasnain, S. E., Kaufman, R. J., and Ramaiah, K. V. (2000). Phosphorylation of serine 51 in initiation factor 2 alpha (eIF2 alpha) promotes complex formation between eIF2 alpha(P) and $\mathrm{eIF} 2 \mathrm{~B}$ and causes inhibition in the guanine nucleotide exchange activity of eIF2B. Biochemistry 39, 12929-12938. doi: 10.1021/bi0008682

Sunita, S., Schwartz, S. L., and Conn, G. L. (2015). The regulatory and kinase domains but not the Interdomain linker determine human double-stranded RNA-activated kinase (PKR) sensitivity to inhibition by viral non-coding RNAs. J. Biol. Chem. 290, 28156-28165. doi: 10.1074/jbc.M115.679738

Tan, X., Sun, L., Chen, J., and Chen, Z. J. (2018). Detection of microbial infections Through innate immune sensing of nucleic acids. Annu. Rev. Microbiol. 72, 447-478. doi: 10.1146/annurev-micro-102215-095605

Taniuchi, S., Miyake, M., Tsugawa, K., Oyadomari, M., and Oyadomari, S. (2016). Integrated stress response of vertebrates is regulated by four eIF2alpha kinases. Sci. Rep. 6:32886. doi: 10.1038/srep32886

Taylor, D. R., Shi, S. T., Romano, P. R., Barber, G. N., and Lai, M. M. (1999). Inhibition of the interferon-inducible protein kinase PKR by HCV E2 protein. Science 285, 107-110. doi: 10.1126/science.285.5424.107

Toth, A. M., Li, Z., Cattaneo, R., and Samuel, C. E. (2009). RNA-specific adenosine deaminase ADAR1 suppresses measles virus-induced apoptosis and activation of protein kinase PKR. J. Biol. Chem. 284, 29350-29356. doi: 10.1074/jbc.M109.045146

Tseng, Y. Y., Liao, G. R., Sen, G. C., Lin, F. Y., and Hsu, W. L. (2015). Regulation of PACT-mediated protein kinase activation by the OV20.0 protein of Orf virus. J. Virol. 89, 11619-11629. doi: 10.1128/JVI.01739-15

Tu, Y. C., Yu, C. Y., Liang, J. J., Lin, E., Liao, C. L., and Lin, Y. L. (2012). Blocking double-stranded RNA-activated protein kinase PKR by Japanese encephalitis virus nonstructural protein 2A. J. Virol. 86, 10347-10358. doi: 10.1128/JVI.00525-12 
Valchanova, R. S., Picard-Maureau, M., Budt, M., and Brune, W. (2006). Murine cytomegalovirus $\mathrm{m} 142$ and $\mathrm{m} 143$ are both required to block protein kinase R-mediated shutdown of protein synthesis. J. Virol. 80, 10181-10190. doi: 10.1128/JVI.00908-06

Walsh, D., and Mohr, I. (2011). Viral subversion of the host protein synthesis machinery. Nat. Rev. Microbiol. 9, 860-875. doi: 10.1038/nrmicro2655

Wang, D., de Weerd, N. A., Willard, B., Polekhina, G., Williams, B. R., and Sadler, A. J. (2017). Auto-phosphorylation represses protein kinase R activity. Sci. Rep. 7:44340. doi: 10.1038/srep44340

Wang, X., Liao, Y., Yap, P. L., Png, K. J., Tam, J. P., and Liu, D. X. (2009). Inhibition of protein kinase $\mathrm{R}$ activation and upregulation of GADD34 expression play a synergistic role in facilitating coronavirus replication by maintaining de novo protein synthesis in virus-infected cells. J. Virol. 83, 12462-12472. doi: 10.1128/JVI.01546-09

Wang, Z., and Mir, M. A. (2015). Andes virus nucleocapsid protein interrupts protein kinase $\mathrm{R}$ dimerization to counteract host interference in viral protein synthesis. J. Virol. 89, 1628-1639. doi: 10.1128/JVI.02347-14

Weber, F., Wagner, V., Rasmussen, S. B., Hartmann, R., and Paludan, S. R. (2006). Double-stranded RNA is produced by positive-strand RNA viruses and DNA viruses but not in detectable amounts by negative-strand RNA viruses. J. Virol. 80, 5059-5064. doi: 10.1128/jvi.80.10.5059-5064.2006

Willis, K. L., Langland, J. O., and Shisler, J. L. (2011). Viral double-stranded RNAs from vaccinia virus early or intermediate gene transcripts possess PKR activating function, resulting in NF-kappaB activation, when the K1 protein is absent or mutated. J. Biol. Chem. 286, 7765-7778. doi: 10.1074/ jbc.M110.194704

Wuerth, J. D., Habjan, M., Kainulainen, M., Berisha, B., Bertheloot, D., Superti-Furga, G., et al. (2020). eIF2B as a target for viral evasion of PKRmediated translation inhibition. MBio 11:e00976-20. doi: 10.1128/ mBio.00976-20
Yang, X., Hu, Z., Fan, S., Zhang, Q., Zhong, Y., Guo, D., et al. (2018). Picornavirus 2A protease regulates stress granule formation to facilitate viral translation. PLoS Pathog. 14:e1006901. doi: 10.1371/journal.ppat.1006901

Yoon, C. H., Lee, E. S., Lim, D. S., and Bae, Y. S. (2009). PKR, a p53 target gene, plays a crucial role in the tumor-suppressor function of p53. Proc. Natl. Acad. Sci. U. S. A. 106, 7852-7857. doi: 10.1073/pnas.0812148106

Zamanian-Daryoush, M., Mogensen, T. H., DiDonato, J. A., and Williams, B. R. (2000). NF-kappaB activation by double-stranded-RNA-activated protein kinase (PKR) is mediated through NF-kappaB-inducing kinase and IkappaB kinase. Mol. Cell. Biol. 20, 1278-1290. doi: 10.1128/mcb.20.4.1278-1290.2000

Zhao, J., Sun, L., Zhao, Y., Feng, D., Cheng, J., and Zhang, G. (2021). Coronavirus Endoribonuclease ensures efficient viral replication and prevents protein kinase R activation. J. Virol. 95:e02103-20. doi: 10.1128/jvi.02103-20

Conflict of Interest: The authors declare that the research was conducted in the absence of any commercial or financial relationships that could be construed as a potential conflict of interest.

Publisher's Note: All claims expressed in this article are solely those of the authors and do not necessarily represent those of their affiliated organizations, or those of the publisher, the editors and the reviewers. Any product that may be evaluated in this article, or claim that may be made by its manufacturer, is not guaranteed or endorsed by the publisher.

Copyright (c) 2021 Cesaro and Michiels. This is an open-access article distributed under the terms of the Creative Commons Attribution License (CC BY). The use, distribution or reproduction in other forums is permitted, provided the original author(s) and the copyright owner(s) are credited and that the original publication in this journal is cited, in accordance with accepted academic practice. No use, distribution or reproduction is permitted which does not comply with these terms. 